\title{
Study on water quality parameters of Linggi and Melaka rivers catchments in Malaysia
}

\begin{abstract}
The Linggi and Melaka rivers catchments are among the most significant watersheds in the west coast of Peninsular Malaysia. However, Malaysia is a tropical country with approximately similar seasonal climate, in the monsoon period, water level of catchment is different. Recently in the supposed domain, due to raising the population and expanding urban areas, demand for water consumption is increased gradually. On the other hand, problem of water pollutions due to industrial activities have been signed out. Therefore, study on water quality and sources of pollutions in these regions became vital for public and private sections. This study was conducted to assess the water quality conditions in both rivers catchments. The observed water quality data for 5 years period (2004-2008) were obtained from Departments of Environmentsôwater quality monitoring stations in Malaysia. Statistical analyses have been carried out on three water quality constituents which are BOD5, NH3-N and TSS. The observed data were compared with the water quality criteria to identify the water quality violation level in both river catchments. Furthermore, the differences in water quality between base and storm flow events were examined using Box and Whisker Plots. Results of this study indicate that TSS and NH3-N are the primary causes for water quality impairment in Linggi River with concentration of about $78.3 \%$ and $81.8 \%$ respectively. However, for Melaka catchment, TSS is identified as the main cause of water quality impairment, when $64.4 \%$ of the total water samples exceed the standard. There are some point sources and non-point sources of water quality impacts in both watersheds. The results of this study would be contributed to development of best management practices for the Linggi and Melaka catchments and similar study areas.
\end{abstract}

Keyword: Water quality assessment; Base and storm flow events; Violation; Land use 